\title{
Abscesos esplénicos asépticos asociados a enfermedad de Crohn
}

\author{
Aseptic splenic abscesses associated with \\ Crohn's disease
}

\author{
Juan Guillermo Gamboa, Roberto Benavides, Oliver Perilla, David Velez, \\ Pablo Castaño, Carolina Pemberthy • Medellín (Colombia)
}

\begin{abstract}
Resumen
Los abscesos asépticos constituyen una entidad en descripción que se ha asociado en la mayoría de los casos a enfermedad inflamatoria intestinal (EII), principalmente enfermedad de Crohn. Su diagnóstico constituye un reto pues exige descartar exhaustivamente infecciones por diversos microorganismos; además porque su aparición puede darse antes, concomitantemente o después del diagnóstico de la EII.

A continuación, presentamos el caso de un paciente de 20 años con pérdida de peso, fiebre persistente, diarrea y dolor abdominal en quien se documentó abscesos esplénicos asépticos y lesiones en piel compatibles con enfermedad de Crohn metastásica y hallazgos inflamatorios inespecíficos en biopsia de tracto gastrointestinal, logrando resolución de todos sus síntomas tras inicio de esteroide.

Palabras clave: absceso, bazo, enfermedad de Crohn, esteroides
\end{abstract}

\begin{abstract}
Aseptic splenic abscesses are an entity in description that has been associated in most cases with inflammatory bowel disease (IBD), mainly Crohn's disease. Its diagnosis constitutes a challenge because it requires exhaustively ruling out infections by different microorganisms and also because its appearance can occur before, concomitantly or after the diagnosis of IBD.

The case of a 20-year-old patient with weight loss, persistent fever, diarrhea and abdominal pain in whom aseptic splenic abscesses and skin lesions compatible with metastatic Crohn's disease and nonspecific inflammatory findings in gastrointestinal tract biopsy were documented, is presented. Resolution of all its symptoms after starting steroid was achieved,

Key words: abscess, spleen, Crohn's disease, steroids.
\end{abstract}

Dr. Juan Guillermo Gamboa: Universidad de Antioquia, Departamento de Medicina Interna. Hospital Pablo Tobón Uribe; Dr. Roberto Benavides: Hospital Universitario San Vicente Fundación; Dr. Oliver Perilla: Universidad Nacional de Colombia; Dr. David Vélez: Hospital Universitario San Vicente Fundación; Dr. Pablo Castaño, Dra. Leidy Carolina Pemberthy López: Universidad de Antioquia. Departamento de Medicina Interna. Medellín (Antioquia)

Correspondencia: Leidy Carolina Pemberthy López. Medellín (Antioquia).

E-mail: caropember@gmail.com

\section{Introducción}

Los abscesos esplénicos son poco comunes, descritos en $0.14-0.7 \%$ de los estudios de autopsias (1). La mayoría de los casos son causados por agentes infecciosos como Staphylococcus aureus, Streptococcus spp., Klebsiella pneumoniae, Escherichia coli, Mycobacterium tuberculosis o Salmonella spp; además existen unos factores de riesgo conocidos como infecciones de cavidad abdominal, endocarditis, diabetes mellitus, malignidad, inmunosupresión o inmunodeficiencias (2). Sin embargo, existe una proporción de abscesos esplénicos que resultan ser asépticos (AEA) y se han asociado con una serie de enfermedades, principalmente enfermedad inflamatoria intestinal, configurándose en una manifestación extrainstestinal y, para muchos autores, como un nuevo síndrome $(3,4)$. Presentamos el caso de un paciente con AEA asociado a enfermedad de Crohn (EC).

\section{Presentación del caso}

Hombre de 20 años, soltero, sin hijos, comerciante; con antecedente de obesidad, apendicetomía y consumo ocasional de marihuana. Consultó inicialmente por cinco días de fiebre objetiva de $39^{\circ} \mathrm{C}$, deposiciones diarreicas no disentéricas y dolor abdominal en fosa iliaca derecha. En la evaluación encuentran signos de irritación peritoneal y le realizaron una laparotomía exploratoria en la que demostraron un conglomerado ganglionar fijo a la raíz del mesenterio con secreción de material purulento. La patología de las biopsias reportó linfadenitis aguda supurativa; prescribieron ampicilina/sulbactam durante cuatro días y lo dieron de alta, aún tenía diarrea.

Después de cuatro días consultó a otra institución por persistencia de la diarrea, recurrencia del dolor abdominal y la fiebre. Además, esta vez refirió pérdida subjetiva de 
peso, náuseas, vómito, brote maculopapular eritematoso y pruriginoso generalizado y varios días con úlceras orales dolorosas. Al examen físico resaltaba el dolor a la palpación en flanco izquierdo, rash macular eritematoso, color salmón en tórax superior, miembros superiores y parte interna de los muslos; además úlceras orales dolorosas en mucosa yugal y paladar blando. En paraclínicos iniciales con anemia normocítica, leucocitosis con neutrofilia, PCR y VSG elevadas, función renal normal, fosfatasa alcalina discretamente elevada e hiperbilirrubinemia directa. Solicitan tomografía de abdomen contrastada que demostró hepatoesplenomegalia, micro abscesos esplénicos, conglomerado de adenopatías necróticas en la raíz del mesenterio, mesenteritis y engrosamiento del íleon terminal. Se consideró salmonelosis y por esa razón iniciaron ceftriaxona y ampliaron estudios en búsqueda de confirmar etiología infecciosa, pero todos fueron negativos: VIH, VDRL, anticuerpos virus hepatitis $\mathrm{C}$, antígeno de superficie virus hepatitis B, IgM Epstein Barr, IgM varicela zoster, hemocultivos \#2, coprocultivo y estudios en materia fecal (Ziehl Neelsen modificado, coccidias y toxina para Clostridium difficile). Se descartó endocarditis infecciosa (ecocardiografía transesofágica normal y hemocultivos negativos), vasculitis, enfermedad linfoproliferativa y tuberculosis intestinal (patología, tinciones $\mathrm{ZN}$ y cultivo para micobacterias negativos).

Finalmente se consideró enfermedad de Crohn: la colonoscopia reportó ileítis distal con microabsceso submucoso caseiforme de $1 \mathrm{~cm}$ y absceso submucoso en ciego de 5 $\mathrm{mm}$. La patología de íleon terminal con cambios reactivos, lámina propia con aumento del infiltrado por linfocitos, plasmocitos y polimorfonucleares neutrófilos y eosinófilos sin granulomas o malignidad. Además, ASCAS positivos (anti Saccharomyces cerevisiae antibodies).

Las biopsias de lesiones cutáneas ahora nodulares, eritemato-violáceas con aspecto contusiforme y algunas pústulas foliculares (Figura 1) son reportadas como enfermedad de Crohn metastásica. Se complementa con entero tomografía

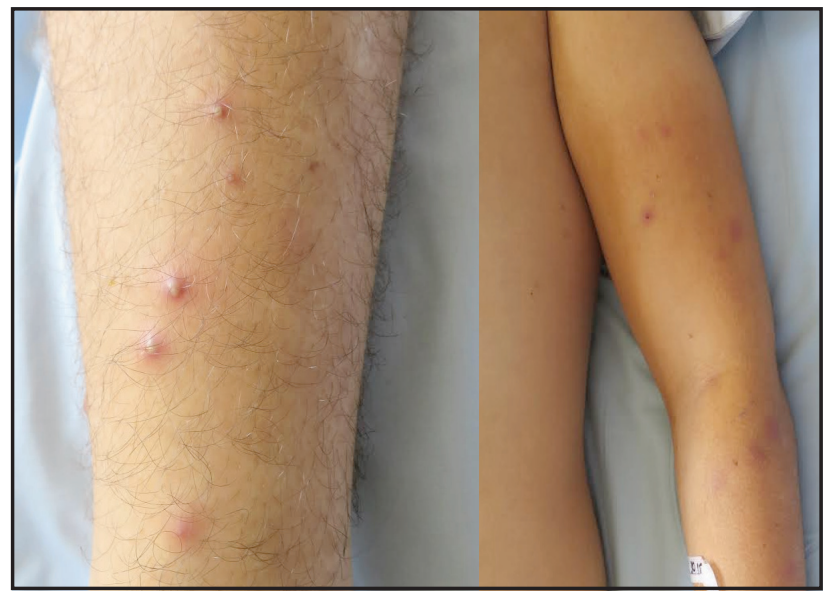

Figura 1. Lesiones cutáneas. que evidencia engrosamiento leve de íleon distal, pero sin signos de enfermedad de Crohn.

A pesar de los hallazgos inespecíficos en biopsias de íleon, teniendo en cuenta el cuadro clínico, su asociación con abscesos esplénicos y luego de descartar infecciones se decide manejar como enfermedad de Crohn con hidrocortisona $50 \mathrm{mg}$ IV cada seis horas; en las primeras 24 horas desaparece el dolor abdominal, la fiebre y respuesta inflamatoria. Sin embargo, luego de 48 horas se suspende por documentación de derrame pleural izquierdo tabicado (sin aislamiento microbiológico) asociado a síntomas respiratorios que requieren decorticación y manejo antibiótico. Finalmente, se considera que todo el cuadro es explicado por sepsis gastrointestinal con siembras pulmonares, pleurales, esplénicas y se da alta.

Luego de cuatro meses reingresa por persistencia de dolor intermitente en hemiabdomen izquierdo exacerbado en los últimos 20 días, asociado a fiebre subjetiva y cuatro días de deposiciones líquidas no disentéricas; además lesiones pretibiales ulceradas melicéricas, induradas sugestivas de eritema nodoso y úlceras orales (Figura 2).

Nuevamente con leucocitosis, neutrofilia, anemia normocítica y elevación de reactantes; hemocultivos y coprocultivos negativos. La tomografía contrastada de abdomen mostró ganglios subcentimétricos mesentéricos, esplenomegalia con múltiples lesiones hipodensas redondeadas coalescentes y con aumento de tamaño. La colonoscopia reportó discreto engrosamiento de íleon distal, cuya patología demostró inflamación crónica activa e hiperplasia linfoide. Se decide aspirado guiado por ecografía de abscesos de bazo obteniendo líquido purulento, achocolatado que resultó ser aséptico (cultivo para aerobios negativos, estudios para hongos y tuberculosis negativos). Se considera que todo el cuadro se explica por enfermedad de Crohn y se inicia

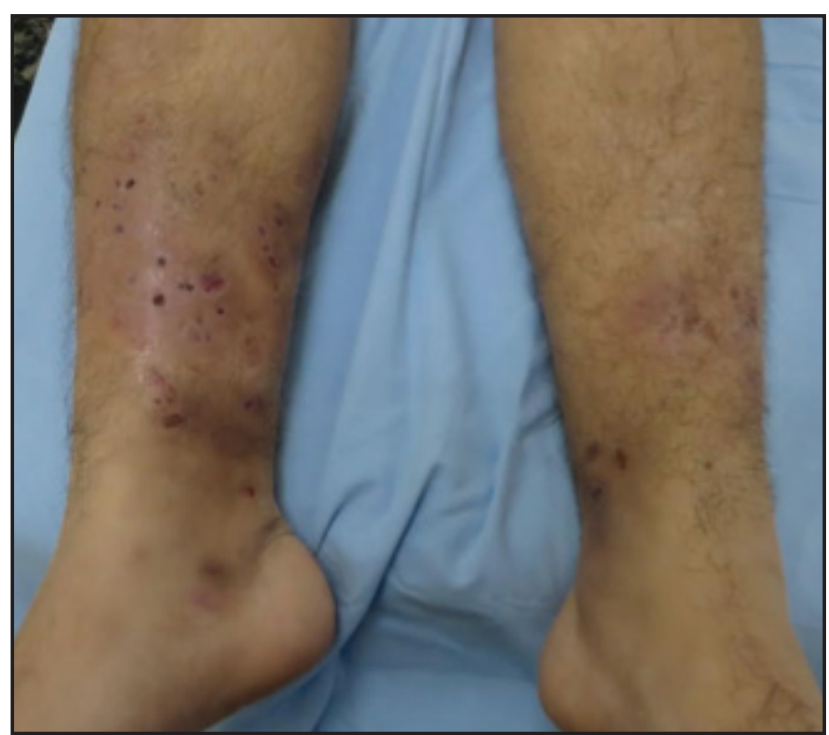

Figura 2. Lesiones pretibiales ulceradas melicéricas. 
tratamiento con prednisolona $60 \mathrm{mg}$ /día. En las primeras 24 horas resuelven el dolor abdominal y desaparece la fiebre, mejoran las lesiones en piel y luego de una semana se da alta con esteroides.

Tras seis meses de tratamiento se documenta disminución marcada de los abscesos esplénicos (Figura 3). Sin embargo, meses después suspende tratamiento y reaparecen las lesiones en piel, cuya biopsia es reportada como Crohn metastásico. Se reinició prednisolona y, posteriormente, se adicionó azatioprina como ahorrador de esteroide con lo que se ha logrado remisión hasta la fecha (Figura 4).

\section{Discusión}

Los abscesos asépticos (AA) como síndrome constituyen una entidad en descripción, pero ya se han propuesto unos criterios diagnósticos basados en los criterios de inclusión utilizados en la serie de registros existente (Tabla 1) (4).

La asociación de abscesos esplénicos asépticos con enfermedad inflamatoria intestinal constituye una rara con-
Tabla 1. Criterios diagnósticos propuestos para Síndrome de abscesos asépticos

\begin{tabular}{|l|}
\hline $\begin{array}{l}\text { Absceso profundo por imágenes, con predominio de polimorfonucleares neutrófilos } \\
\text { cuando se realiza una punción. }\end{array}$ \\
\hline Cultivos negativos y estudios microbiológicos que descartan proceso infeccioso. \\
\hline $\begin{array}{l}\text { Falla al manejo antibiótico: en general dos semanas para terapia convencional y tres } \\
\text { meses para medicamentos antituberculosos. }\end{array}$ \\
\hline $\begin{array}{l}\text { Mejoría clínica rápida al día siguiente de inicio de esteroides }(0.5-1 \mathrm{mg} / \mathrm{kg} / \mathrm{día}), \\
\text { seguido de mejoría radiológica después de un mes de terapia. }\end{array}$ \\
\hline
\end{tabular}

dición con menos de 50 casos reportados, la mayoría en Europa. Configuran un gran reto diagnóstico y terapéutico. El registro más grande en el mundo sobre AA cuenta con 30 pacientes, de los cuales 21 estaban asociados a EII (17 con enfermedad de Crohn, 3 colitis ulcerativa, 1 colitis indeterminada)(5). En este grupo la edad promedio de diagnóstico de los abscesos es 24.4 años, debutan con fiebre, pérdida de peso y dolor abdominal, diarrea en $20 \%$ (independiente de

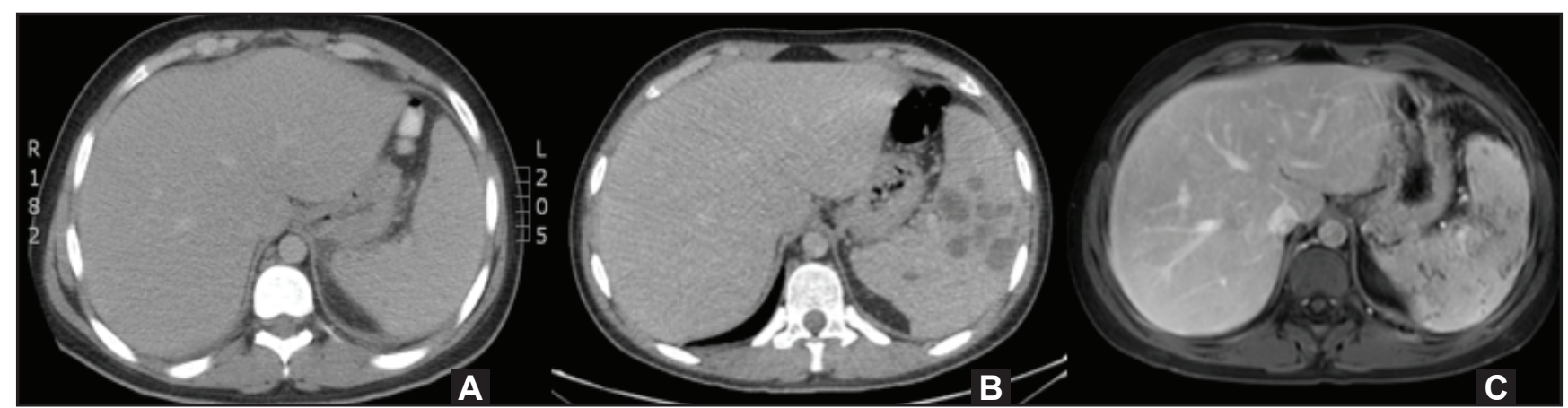

Figura 3. A. Tomografía contrastada de abdomen en segunda hospitalización cuando se documentó por primera vez abscesos esplénicos asépticos. B. Tomografía contastada durante tercera hospitalización, con aumento del tamaño y confluencia de los abscesos esplénicos, venía sin tratamiento específico. C. Tomografía contrastada luego de seis meses de manejo con esteroides, logrando reducción en el tamaño de las lesiones en bazo.
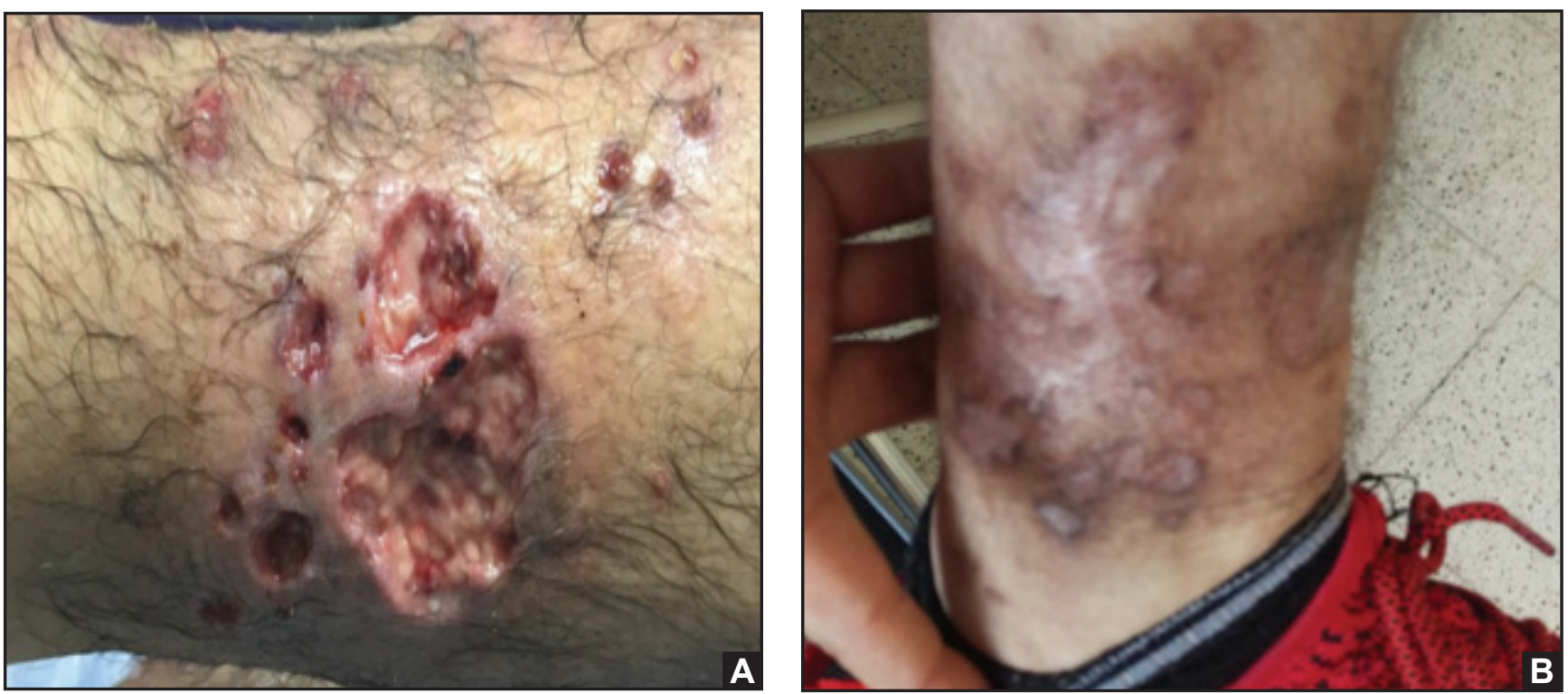

Figura 4. Comportamiento de lesiones cutáneas según tratamiento. A. Lesiones cutáneas en miembros inferiores que aparecieron al suspender manejo inmunosupresor. B Mejoría de lesiones cutáneas luego de semanas de tratamiento con prednisolona y azatioprina. 
la actividad de la EII) así como elevación en la velocidad de sedimentación, leucocitosis (80\%) y anemia (43\%). Las pruebas de función hepática se alteran en $38 \%$ de los casos (colestasis o patrón hepatocelular).

Los abscesos son de localización principalmente abdominal, en el siguiente orden de frecuencia: bazo, ganglios linfáticos más el bazo, ganglios linfáticos solos, hígado más ganglios linfáticos, hígado sólo y riñón. Puede presentarse compromiso extraabdominal en pulmón, cerebro, testículos y piel; dentro de las manifestaciones cutáneas se describe dermatosis neutrofílicas y aftas orales. Además, se acompaña de artralgias y mialgias en 20-23\%. Los estudios microbiológicos son negativos, incluyendo la procalcitonina, así como los estudios de autoinmunidad, tal como se demostró en nuestro paciente.

Así mismo, es característica la falta de respuesta completa al uso de antibióticos y la marcada mejoría clínica en las primeras 24 horas de uso de esteroides en la mayoría de pacientes descritos en la literatura, por cuanto se convierte en la primera línea de tratamiento. Se ha recurrido además al uso de azatioprina, ciclofosfamida, metotrexate, infliximab, adalimumab y esplenectomía en casos con pobre respuesta a manejo inicial (3). Siempre se debe contar con terapia de mantenimiento porque las recaídas son muy comunes (hasta 57\%), lo que se corroboró en nuestro paciente tras la suspensión transitoria de esteroides.

El diagnóstico de enfermedad inflamatoria intestinal puede hacerse antes, concomitante o después del diagnóstico de los abscesos asépticos (33\% respectivamente) (5). Incluso hay un reporte donde se documentan los abscesos asépticos como manifestación inicial de la enfermedad de Crohn (6). Por lo anterior, en el caso de nuestro paciente, aunque la biopsia de íleon no fue específica para el diagnóstico de la enfermedad de Crohn, ésta si se documentó en las lesiones cutáneas, tenía ASCAS positivos sumado el resto del cuadro clínico; además es probable que en el futuro presente los síntomas y los cambios histológicos de una enfermedad inflamatoria intestinal.

\section{Conclusión}

Los abscesos esplénicos asépticos son una entidad clínica en descripción, asociada principalmente con enfermedad inflamatoria intestinal, específicamente enfermedad de Crohn. Constituyen un reto diagnóstico pues exige descartar exhaustivamente cualquier proceso infeccioso, corroborar la ausencia de respuesta al antibiótico y una marcada mejoría clínica en las primeras 24 horas del tratamiento con esteroides. Se debe tener en cuenta que el diagnóstico de la EII puede darse antes, concomitantemente y luego de la documentación de los abscesos asépticos; además presenta un importante porcentaje de recaídas, todo lo cual implica un seguimiento clínico estrecho de los pacientes a largo plazo.

\section{Referencias}

1. Liu YH, Liu CP, Lee CM. Splenic abscesses at a tertiary medical center in Northern Taiwan. J Microbiol Immunol Infect 2014; 47 (2): 104-8.

2. Jordan AJ, Becker KP, Sertemir M, Neff KW, Adam R, Schroten H, et al Multiple aseptic splenic abscesses in a 15 year old patient. BMC Gastroenterol 2014; (6): 14:20.

3. Bollegala N, Khan R,. Scaffidi MA, Al-Mazroui A, Tessolini J, Showler A, Colak E, et al. Aseptic Abscesses and Inflamatory Bowel Disease: Two Cases and Review of Literature. Can J Gastroenterol Hepatol 2017; (2017): 1-8.

4. André MF, Aumaître O. Aseptic abscesses síndrome. Rev Med Interne 2011; 32 (11): 678-88.

5. André MF, Piette JC, Kémény JL, Ninet J, Jego P, Delèvaux I, et al. Aseptic abscesses: a study of 30 patients with or without inflammatory bowel disease and review of the literature. Medicine (Baltimore). 2007; 86 (3): 145-61.

6. Brooks J, Ghaffari G. Aseptic Splenic Abscess as Precursory Extraintestinal Manifestation of Inflamatory Bowel Disease. Case Rep Med 2014; Article ID: 684231. 